eCommons@AKU

January 2018

\title{
Academic incivility in modern generation of nursing students
}

Laila Akber Cassum

Aga Khan University, laila.cassum@aku.edu

Follow this and additional works at: https://ecommons.aku.edu/pakistan_fhs_son

Part of the Medical Education Commons, Nursing Administration Commons, Nursing Midwifery Commons, and the Occupational and Environmental Health Nursing Commons

\section{Recommended Citation}

Cassum, L. A. (2018). Academic incivility in modern generation of nursing students. i-manager's Journal on Nursing, 7(4), 6-9. Available at: https://ecommons.aku.edu/pakistan_fhs_son/327 


\title{
ARTICLES
}

\section{ACADEMIC INCIVILITY IN MODERN GENERATION OF NURSING STUDENTS}

\author{
By

\begin{abstract}
LAILA AKBER CASSUM
Senior Instructor, Aga Khan University School of Nursing and Midwifery, Karachi, Pakistan.
\end{abstract} \\ Date Received: 19/01/2018 \\ Date Revised: 29/01/2018 \\ Date Accepted: 08/02/2018
}

\section{ABSTRACT}

Incivility in nursing academia and workplace is one of the emerging and complex issues in recent years, and can have substantial consequences on the organizational benchmark as well as on the teaching and learning milieu of the institution. Growth of academic incivility among the modern and diversified generation of students can have a profound destructive impact on their academic life and professional career. Impolite and discourteous attitude and behavior in a classroom atmosphere can originate from the learners as well the teachers, which can significantly impact the critical thinking and learning outcomes of the learner. This matter needs to be addressed based on the institutional policy and standards so that professional leaders for tomorrow can be extracted from the current and upcoming generation.

Keywords: Academic Incivility, Nursing Students, Academia.

\section{INTRODUCTION}

With the advent of globalization, in the last couple of decades, the millennial generation have matured and are growing in an extremely electronically filled, web based, and socially networking world. The millennial generation have been following the mantra of chasing their dreams and goals consistently relatively to the previous generations. The learners of the millennial cohort comprise of the most ethnically diverse generations belonging to various fields and professions including Nursing and Medicine. They are advanced and have high prospects in academic as well as in workplace domains. Diversity of learners in academia can be a strength if taken positively nevertheless, it can have a substantial negative impact in the spheres of quality, competency and satisfaction level. In nursing education, university educators encounter incivil and inappropriate behavior of students that are quiet distressing and troubling during the process of teaching and learning. Incivility in nursing academia and workplace is one of the emerging and complex issues in recent years, and can have considerable consequences on the organizational benchmark, teaching and learning milieu of the institution and the quality of coming up generation in health care industry.

\section{Significance of the issue}

It has been observed and experienced several times that the contemporary group of learners are impolite and disrespectful and interrupt the discipline and learning atmosphere. This is the most significant and evolving concern of the educators working in the scholastic environment. Further, this issue needs to be worked upon as incivility will not only impact on personal and professional lives in a student role, but if it is ignored it will eventually influence the generation of uncivil employee having behavioral complexities, violence, and aggression. Examples of the most common disrespectful behavior are: being irregular and unpunctual for the scheduled didactic class sessions and skills demonstration, playing games on gadgets, chatting on social media during class, leaving the class without excuse or non-genuine excuse, coming unprepared for the session, continuous talking and murmuring, and inattentiveness during the class. Besides this, the students have fearless and carefree attitude despite of frequent reminders for maintaining professionalism. Though the students have positive attributes too nevertheless, the negative characteristics of 


\section{ARTICLES}

the learners of the class can overpower the positive ones, and can also obstruct the learning process of the students who have serious attitude towards their learning and profession.

This non-serious, carefree, and least bothered kind of an attitude of the students, can highly influence on the quality of care of the patients when these students will transiting into their professional role. In addition, questions arise that what sort of role models will they be, when they will shift into the roles of fully prepared nurses at workplace.....?

This is the most alarming subject, which needs to be mulled upon. There has been a gradual transformation in the mindsets, perceptions, mannerisms, actions and approach of viewing and analyzing the situation differently by diverse group of students, nurse educators, and nurses at workplace in the domains of academia and workplace environment. The regulatory policies and moral standards to maintain discipline, and to follow the institutional benchmarks, and to implement the way as the institution expects is no more a priority for the modern generation of the students. In contrast, modern age group of learners is entirely different with diverse set of values and beliefs. Personal upbringing at home and professional grooming at the academic institution where the mentors, teachers, and advisors play an exemplary role in shaping the personality of the learner are significant elements that influence the learner as a whole, Thinking aloud.... This hidden gap in the growth of the generation ahead can have extensive destructive impact on their professional career as well as on the image of the nursing profession.

We cannot refrain from the fact that these students belong to era of web technology and gadgets, with different genetic makeup and environmental exposure. They are quick learners, and can retrieve tons of information in just a single click. Furthermore, media and technology has also played an additional role in transforming their thoughts, ethical values and beliefs, and principles to move along with the world's place. However, the negative perspective where the adaptation of all forms of media, and web environment has substantially affected their values and beliefs and ethical principles, which is evidently reflected in the form of uncivil conduct and demeanor. It is highly imperative that personal philosophies, such as honesty, accountability, respect, justice, and trust are the essential elements to maintain academic integrity and professionalism which appears to be missing in their behaviors.

\section{Literature Review}

Literature from various research studies supports the fact that the current generation of nursing students are much uncivil and discourteous compared to the previous cohorts of students decades ahead. Incivility is a broad term extending from unprofessional and insulting comments and actions to violence, however, the focus will be restricted to some uncivil behaviors which can disturb the teaching and learning atmosphere. Apart from Nursing profession, this issue also exists in other disciplines of health such as Medicine as well (Ronan-Bentle et al., 201 1). Uncivil behavior includes those comments and actions which are considered impolite and discourteous ranging from offensive remarks to volatile and violent behavior (Shaeffer, 2013; Deering, 2011). In an educational environment, incivility includes those behaviors which interrupts the professional environment necessary for effective teaching and learning (Clark and Springer, 2010). This disruption can be from faculty as well as student (Altimiller, 2012). A descriptive study reported some student activities such as making sarcastic comments, not paying attention in class, using cell phones, dominating class discussion were considered as uncivil, whereas revoking class without prior notification, being unavailable after the class, not permitting for open ended discussion, criticizing students were some of the impolite nurse educators behaviors (Clark and Springer, 2007; Altimiller, 2012). Incivility grows and prevails when the uncivil attitudes of student are tolerated, and no stringent action is taken at the right time by the academic institution, then the students also consider such behaviors as a norm, and repeatedly carry out during the class sessions.

One of the dimensions in the creations and progression of a uncivil academic environment is that the nurse educators are unwilling to tackle these impolite and discourteous behaviors and manners (Deering, 2011). The teacher handles and considers the issue mildly and does not report to the higher administration (Luparell, 2003). In addition, due to cultural paradigm shift, many of the behaviors are 


\section{ARTICLES}

taken as standard. In large classroom format, teachers intentionally or unintentionally perpetrate discourtesy themselves (Hanson, 2000). It is quite alarming that if tomorrow's young leaders will have such unprincipled behaviors and actions, then the outcome can be quiet destructive for self and profession. One of the findings of Clark and Springer study reports that these uncivil experiences not only disturbs educational atmosphere, the students are also left untrained for their potential quarrels at workplace (Clark and Springer, 2007).

Another, perspective is that the faculty sets examples for the students and it is vital that positive behaviors should be encouraged and inculcated in them. Positive, friendly, yet firm attitude of the faculty can generate a considerable impact in shaping the personality of the learner to be more pleasant, friendly than hostile which can also result in an engaging classroom atmosphere. It is seen that the students presume to behave the same way if the teacher behaves unprofessionally and amateurishly, because they consider their teachers as their role models.

\section{Consequences of Incivility on Students and Teachers} Incivility can lead to devastating consequences on students and educators. High order critical thinking cannot exist in a stressful and uncivil atmosphere. If the faculty comes across with several uncivil behaviors in the classroom, then these are considerable enough to induce frustration, annoyance, apprehension, and self doubt (Shaeffer, 2013). If the student encounter unacceptable attitude from teacher, it can make the learner defensive, anxious, and aggressive and can alter the learning process (Shaeffer, 2013; Clark, 2008).

\section{Interventions to Promote Civility}

What should be done to produce well-mannered students? The rule of thumb is and it should be embedded in learners that communication skills, professional mannerisms, and ettiquettes are as important as clinical skills, and these needs to be followed consistently. Any deviation or inability to follow the academic rules can result in serious repercussions. Continuous educational sessions on professional communication skills, conflict resolutions, and group dynamics should be the part of the orientation programe before the commencement of the classes
(Luparrell, S, 2011). In addition, reading of the student's handbook should be made mandatory, so that the students are well aware of the academic institution policy and standards. Monthly journal club of the students should be introduced where they will develop an understanding on civility, collegiality, and collaboration (Jenkins et al., 2013). A very important step is to cater the psychological needs of the students in the institution which can welcome healthy classroom environment (Kerr andValenti, 2009).

\section{Conclusion}

The challenges encountered by teaching force are real so do the pressures faced by the student. The main aim is to foster environment free of uncivil behaviors so that the learning can be maximized and professional leaders can be extracted from today's students workforce. Creating an atmosphere that cultivate academic integrity requires a cultural change which will take time, but such a goal must be chased.

\section{References}

[1]. Altmiller, G. (2012). Student perceptions of incivility in nursing education: Implications for educators. Nursing Education Perspectives, 33(1), 15-20.

[2]. Clark, C. M., \& Springer, P. J. (2007). Incivility in nursing education: A descriptive study of definitions and prevalence. Journal of Nursing Education, 46(1), 7-14.

[3]. Clark, C. (2008). Student perspectives on faculty incivility in nursing education: An application of the concept of rankism. Nursing Outlook, 56(1), 4-8.

[4]. Clark, C. M., \& Springer, P. J. (2010). Academic nurse leaders' role in fostering a culture of civility in nursing education. Journal of Nursing Education, 49(6), 319-325.

[5]. Deering, C. (2011). Managing Disruptive Behaviour in the Classroom. College Quarterly, 14(3), 1-6.

[6]. Hanson, M. F. (2000). Classroom incivility: Management practices in large lecture courses (Doctoral dissertation, University of South Dakota).

[7]. Jenkins, S. D., Kerber, C. S., \& Woith, W. M. (2013). An intervention to promote civility among nursing students. Nursing Education Perspectives, 34(2), 95-100.

[8]. Kerr, M. M., \& Valenti, M. W. (2009). Controls from within the classroom: Crises or conversations? Reclaiming 


\section{ARTICLES}

Children and Youth, 17(4), 30.

[9]. Luparell, S. (2003). Critical Incidents of Incivility by Nursing Students: How Uncivil Encounters with Students affect Nursing Faculty [dissertation]. Lincoln: University of Nebraska.

[10]. Luparell, S. (201 1). Incivility in nursing: The connection between academia and clinical settings. Critical Care
Nurse, 31(2), 92-95.

[11]. Ronan-Bentle, S. E., Avegno, J., Hegarty, C. B., \& Manthey, D. E. (2011). Dealing with the difficult student in emergency medicine. International Journal of Emergency Medicine, 4(39), 1-6.

[12]. Schaeffer, A. (2013). The effects of incivility on nursing education. Open Journal of Nursing, 3(02), 178-181.

\section{ABOUT THE AUTHOR}

Laila Akber Cassum is currently working as Senior Instructor at Aga Khan University School of Nursing and Midwifery, Karachi, Pakistan. She did her Masters of Science in Nursing in 2015, Baccalaureate of Science in Nursing (Post RN - BScN) in 2003, and Diploma in Nursing in 1998 from the same institution. She has also currently completed her Dip/oma in Midwifery from Murshid School of Nursing and Midwifery. She has worked as a Critical Care Nurse (CCN) for three years in Cardiac Intensive Care Unit (CICU) at Aga Khan University Hospital, Karachi, Pakistan (AKUH). Then, she pursued her career as a Nurse Educator in facilitating the coming generation of students in field of Nursing. She had also worked in the domain of research in the capacity of Research Coordinator in different research studies. Her first independent research as a principal investigator was on elderly people living in shelter homes. The research was first of its kind conducted on elderly people living in shelter homes in Karachi, Pakistan. She have completed her undergraduate nursing education with high achievements and awards and the author of papers in reputed peer reviewed and indexed Journals and many are about to publish. Her research interest areas are Geriatric and Ageing Population, Non-Communicable Diseases (NCDs), Education, and Critical Care. 